\title{
ARCHIVES
Of
}

\section{Properties of Sinters Produced from Commercially Available Powder Mixtures}

\author{
J. Borowiecka-Jamrozek $^{\text {a,* }}{ }^{\text {, J. Lachowski }}{ }^{\text {b }}$ \\ ${ }^{a}$ Faculty of Mechatronics and Machine Design, Department of Applied Computer Science and Armament Engineering, \\ ${ }^{b}$ Faculty of Management and Computer Modelling, Department of Applied Computer Science and Applied Mathematics, \\ Kielce University of Technology, Al. Tysiąclecia PP. 7, 25-314 Kielce, Poland \\ *Corresponding author. E-mail address: jamrozek@tu.kielce.pl
}

Received 10.06.2016; accepted in revised form 28.07.2016

\begin{abstract}
This paper discusses the mechanical properties of a material fabricated from commercially available metal powder mixtures designed for use as a metal matrix of diamond impregnated composites. The mixtures with the catalogue numbers CSA and CSA800 provided by a Chinese producer are suitable for experimental laboratory testing. The specimens were fabricated in a graphite mould using hot pressing. The material was tested for density, porosity, hardness, and tensile strength under static loading. A scanning electron microscope (SEM) was used to analyze the microstructure and cleavage fracture of broken specimens. It was essential to determine how the chemical composition and the fabrication process affected the microstructure and properties of the material. The properties of the sinters were compared with those of hot pressed specimens fabricated from sub-micron size cobalt powder (Cobalt SMS). Although the as-consolidated material is inferior to cobalt, it displays a favourable combination of hardness, yield strength and ductility, and seems to have a great potential for moderate and general purpose applications.
\end{abstract}

Keywords: Composites, Diamond, Matrix, Sinters, Hot pressing

\section{Introduction}

Over the past decades, cobalt has been commonly used as a matrix material in diamond impregnated composites designed for stone cutting tools. Technologically, cobalt has numerous advantages [1-5]. It is available in the form of powders that differ in purity as well as the shape and size of particles. Cobalt powders can be compacted to a density similar to the theoretical density if the temperature is not higher than $850{ }^{\circ} \mathrm{C}$. During powder consolidation, cobalt is reported to moderately affect graphitization; it also causes a reduction in the mechanical properties of diamond crystals. Sintered cobalt alloys show high tensile strength properties and good ductility. A cobalt matrix has very good retentive properties. The addition of copper, tin, bronze or tungsten carbide to a cobalt-based powder mixture may substantially change the abrasion resistance of the matrix [6-10].

The main problem concerning the application of cobalt is that its price has increased significantly over the last few years. The relationship between the prices of cobalt and diamond has also changed. The price of industrial diamond has dropped considerably as a result of its increased production in China. Now the high cost of production of diamond impregnated tools is primarily attributable to the high price of the material used for the matrix. All the changes in the prices of raw materials and a relative decrease in the production costs have forced tool manufacturers and metallic powder producers to look for new cheaper matrix materials to replace cobalt [11]. Research on the subject began in the mid 1990s with a study of cheap iron powders and their wider application as a base metal. Fine carbonyl iron powders are most suitable for powder premixes 
[12]. High-tech manufacturing companies specializing in metallic powders offer specially developed mixtures ready to use for diamond impregnated tools [13]. The main advantage of these powders is their reasonable price and ease of consolidation by hot pressing. A lot of theoretical and experimental research work is now being conducted on these powders. Being available also outside China, the ready-to-use powder mixtures are replacing powders obtained in a traditional way; they are considered an economical substitute for cobalt used in circular saws for cutting natural stone[14].

This paper describes a laboratory experimental study of commercially available powders supplied by a Chinese manufacturer. According to the information provided by the manufacturer, the powders are universal and can be used directly in the production of diamond impregnated tools for cutting different stones and ceramics. The investigations involved analyzing the influence of the chemical composition and the conditions of the fabrication process on the microstructure and mechanical properties of the sintered CSA and CSA800 powders [14]. The properties of the materials were compared with the properties of sintered specimens produced by hot pressing from SMS-type Cobalt powder [15].

\section{Experimental Procedure and Results}

The study was conducted for sintered specimens obtained by hot pressing from ready-to-use iron-based powder mixtures CSA (Fig. 1a) and CSA800 (Fig. 1b) - supplied by a Chinese producer [14].

Prior to consolidation, the CSA and CSA800 powders were extensively analyzed using a JSM-7100F scanning electron microscope equipped with an OINA-AZtec X-ray microanalysis system. According to the supplier's suggestion, the powders were consolidated by hot pressing in a graphite mould, which allows simultaneous fabrication of 10 specimens with nominal dimensions of $\sim 7 \times 6 \times 40 \mathrm{~mm}$. Because the mould was made of graphite, the maximum pressure applied was $35 \mathrm{MPa}$. Hot pressing was performed in nitrogen using an ARGA CAR1001 hot press furnace.

The sintered specimens were measured for density and hardness. The measurements of density involved weighing the specimens in air and in water with WPA120 hydrostatic scales. The density data was then used to calculate the material porosity. The hardness of the sintered materials was established by means of Vickers tests using a load of $98 \mathrm{~N}$ according to the norm PN EN ISO 6507-1:2007. The parameters of the hot pressing process and the results of the density and hardness measurements are given in Table 1. a)

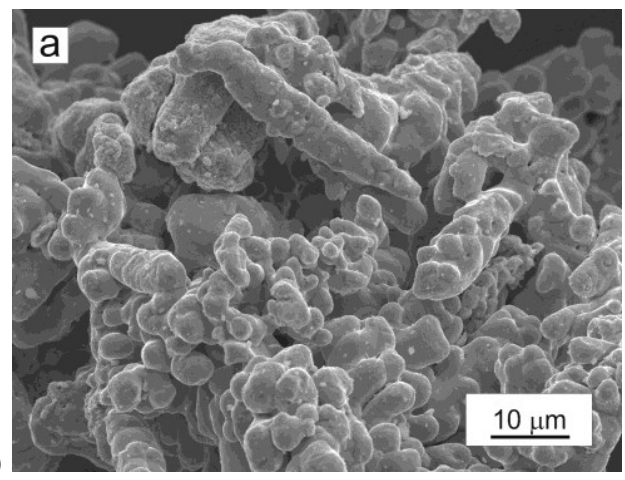

b)

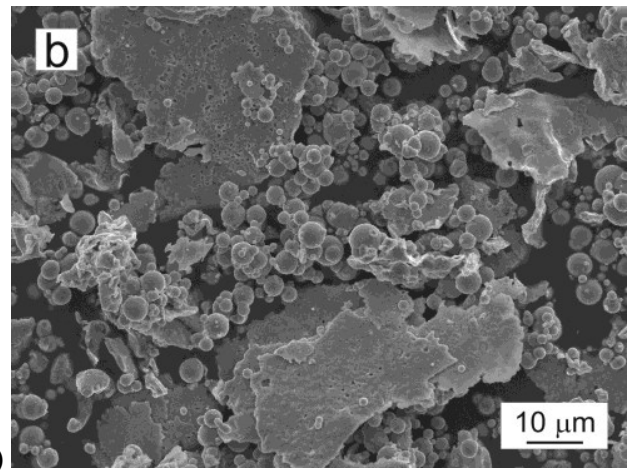

Fig. 1. SEM images of the powders studied: a) CSA b) CSA800

The tensile strength tests were performed using an INSTRON 4502 universal testing machine. From the experimental data it was possible to calculate: the offset yield strength $\mathrm{R}_{0.2}$, the ultimate tensile strength $R_{m}$, and the relative elongation $(\varepsilon)$. The results of the tensile tests with stress-strain curves obtained for the sintered CSA and CSA800 powders are illustrated in Table 2 and Fig. 2.

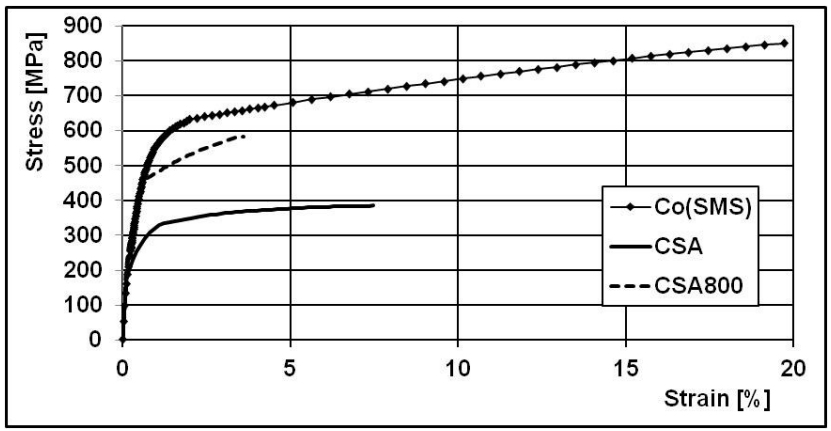

Fig. 2. Stress-strain curves for the sintered CSA, CSA800 and Co(SMS) powders

After tensile testing, the specimens were subjected to fractographic examinations using a JSM-7100F scanning electron microscope integrated with an OINA-AZtec system. Figure 3 shows the fracture surfaces of the materials, while Fig. 4 illustrates their microstructures. 
Table 1.

Parameters of the hot pressing process and the measurement results concerning the material density, porosity and hardness

\begin{tabular}{clcccc}
\hline Powder & Hot pressing conditions & $\begin{array}{c}\text { Density } \\
{\left[\mathrm{g} / \mathrm{cm}^{3}\right]^{(1)}}\end{array}$ & $\begin{array}{c}\text { Theoretical } \\
\text { density }\left[\mathrm{g} / \mathrm{cm}^{3}\right]\end{array}$ & $\begin{array}{c}\text { Porosity } \\
{[\%]}\end{array}$ & HV10 \\
\hline CSA & $850^{\circ} \mathrm{C} / 35 \mathrm{MPa} / 3 \mathrm{~min}$ & $8.06 \pm 0.02$ & 8.36 & 3.60 & $145.5 \pm 9.9$ \\
\hline $\mathrm{CSA} 800$ & $850^{\circ} \mathrm{C} / 35 \mathrm{MPa} / 3 \mathrm{~min}$ & $8.13 \pm 0.01$ & 8.33 & 2.51 & $223.1 \pm 10.2$ \\
\hline $\mathrm{Co}(\mathrm{SMS})$ & $850^{\circ} \mathrm{C} / 35 \mathrm{MPa} / 3 \mathrm{~min}$ & $8.74 \pm 0.04$ & 8.90 & 1.80 & $271.0 \pm 3.0$ \\
\hline
\end{tabular}

${ }^{(1)}$ scatter intervals estimated at $90 \%$ confidence level

Table 2.

Results of the static tensile strength testing

\begin{tabular}{cccccc}
\hline Powder & $\begin{array}{c}\text { Young's modulus E* } \\
{[\mathrm{GPa}]}\end{array}$ & Poisson's ratio* & $\begin{array}{c}\text { Offset yield strength } \\
\mathrm{R}_{0.2}{ }^{(1)} \\
{[\mathrm{MPa}]}\end{array}$ & $\begin{array}{c}\text { Ultimate tensile } \\
\text { strength } \mathrm{R}_{\mathrm{m}}{ }^{(1)} \\
{[\mathrm{MPa}]}\end{array}$ & $\begin{array}{c}\text { Maximum elongation } \\
\varepsilon^{(1)}[\%]\end{array}$ \\
\hline CSA & 156 & 0.32 & $251.7+/-7.6$ & $382.8+/-13.9$ & $8.2+/-2.2$ \\
\hline CSA800 & 158 & 0.32 & $401.7+/-42.5$ & $594.0+/-11.9$ & $3.6+/-0.22$ \\
\hline Co (SMS) & 205 & 0.30 & $404.5+/-25.4$ & $865.0+/-12.0$ & $19.5+/-1.5$ \\
\hline
\end{tabular}

* acoustic emission measurements

${ }^{(1)}$ scatter intervals estimated at $90 \%$ confidence level
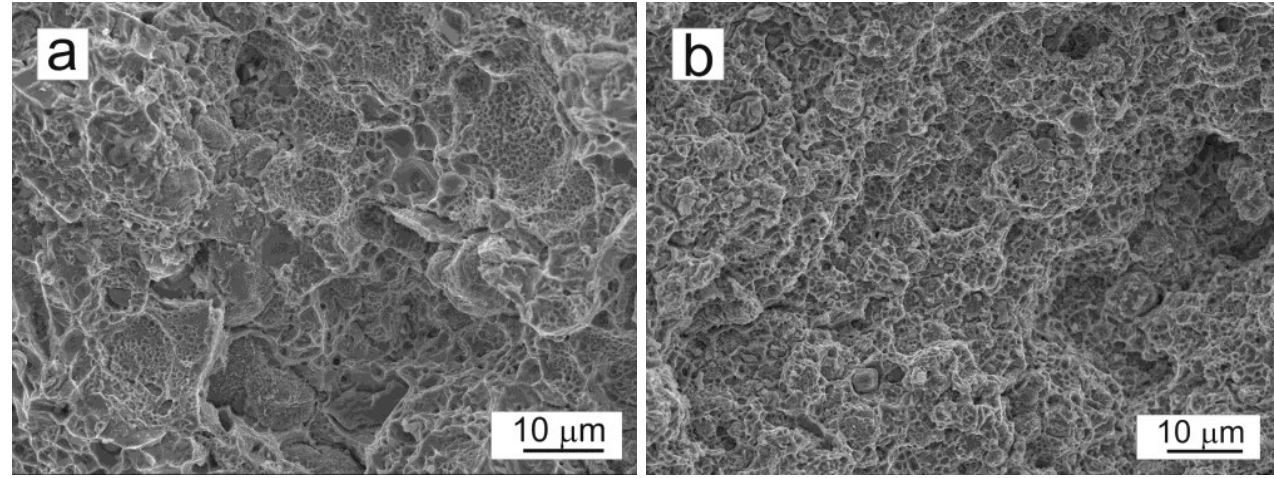

Fig. 3. Fracture surfaces after tensile strength tests a) CSA, b) CSA800

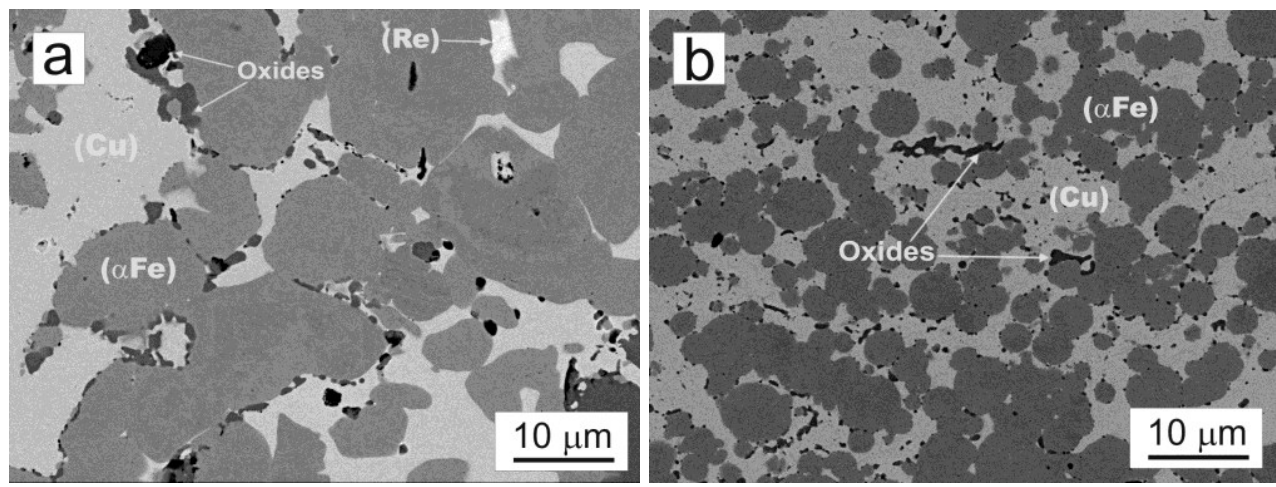

Fig. 4. Microstructure of the sintered powders a) CSA, b) CSA800

\section{Discussion and Conclusions}

The EDS elemental analysis of the surface of the sintered CSA specimens shows that it is impossible to distinguish between the elements, which suggests that it is an alloy powder. Spectra of the sintered particles indicate that the powder contains $45 \% \mathrm{Fe}$, $50 \% \mathrm{Cu}, 3 \% \mathrm{Zn}$ and $2 \% \mathrm{Sn}$.
Spectra of the sintered CSA 800 powder reveal that it contains crude carbonyl iron particles mixed with irregular much coarser particles of alloyed bronze (B663). The data shows that bronze contained $6 \%$ zinc, up to $3 \%$ tin and up to $1 \%$ lead.

As shown in Table 1, the CSA and CSA800 alloys have an interesting combination of mechanical properties. The CSA alloy does not possess high hardness (145.5 HV10), high tensile strength $(382.8 \mathrm{MPa})$ or high offset yield strength $(251.7 \mathrm{MPa})$, 
but it has a high maximum elongation of $8.2 \%$. The CSA800 alloy, on the other hand, is characterized by high hardness (223 HV10), high tensile strength (591 MPa) and high offset yield strength (404 MPa) with the maximum elongation being 3.3\%.

The fractographic examinations indicate that the fracture surfaces of both materials have ductile dimple-like features.

The EDS elemental analysis performed on the metallographic sections of the sintered CSA and CSA800 powders shows their complex multi-phase microstructure. It confirms that the CSA powder contains $\mathrm{Fe}(42-52 \% \mathrm{wt}), \mathrm{Cu}(48-53 \%), \mathrm{Zn}(2-3 \%)$, and $\mathrm{Sn}$ (2\%); rare earth metals, including $\mathrm{Ce}, \mathrm{La}, \mathrm{Sm}$, and $\mathrm{Y}$ were also found, and their amounts were below 3\%. The SEM image in Fig. 4a shows the alloy microstructure; the sintered material consists of a carbon-rich $\alpha-\mathrm{Fe}$ solution, a solid solution of $\mathrm{Sn}$ and $\mathrm{Zn}$ in $\mathrm{Cu}$, dark areas with metal oxides and sparse well-separated white areas with a solid solution of rare earth metals in tin and copper, mainly Ce $(21 \%)$, La (6\%) and Sm (3\%). The EDS elemental analysis carried out on metallographic sections of the sintered CSA800 powder confirmed its multi-phase microstructure. The study of CSA revealed the presence of $\mathrm{Fe}(42-57 \% \mathrm{wt}), \mathrm{Cu}$ (35$51 \%), \mathrm{Zn}(3-4 \%), \mathrm{Sn}(3 \%), \mathrm{Pb}(<1 \%)$ and rare earth metals (in minute quantities).

From Fig. $4 \mathrm{~b}$ it is evident that the alloy is composed of a carbonrich $\alpha-\mathrm{Fe}$ solution, a copper solution, which is actually a solid solution of $\mathrm{Sn}$ and $\mathrm{Zn}$ in $\mathrm{Cu}$ and dark areas with metal oxides. Although the energy-dispersive $\mathrm{X}$-ray spectra showed $\mathrm{Pb}$ peaks, no well-separated $\mathrm{Pb}$ inclusions were observed in the material structure.

The conclusions can be summarized as follows:

a) The materials are noteworthy because of their reasonable price, ease of consolidation by hot pressing and a possibility to substantially change their strength properties and ductility.

b) The properties of the materials can be changed by appropriately altering their chemical composition, which is achieved by adding such elements as $\mathrm{Ni}, \mathrm{WC}, \mathrm{W}$, or Co. The composition of the CSA material is easy to modify, because its strength parameters are relatively low. The material can be used either unmodified or modified by adding some metal elements.

c) It is also possible to alter the temperature during hot pressing. The CSA alloys have a density equal to $>97 \%$ of the theoretical density after a short holding time of 3 minutes at a pressure of $35 \mathrm{MPa}$ and a temperature of $800-880^{\circ} \mathrm{C}$.

d) The matrix fabricated from CSA or CSA800 shows very good retention of diamond particles during use of diamondimpregnated tools because the materials contain elements acting as catalysts in the production of synthetic diamond. During cooling that follows hot pressing, mechanical and chemical bonding takes place between the diamond particles and the matrix; the bonding is dependent on the elastic and plastic properties of the matrix material. The retention of diamond particles in matrices with different mechanical properties was analyzed by the author in her earlier works [9]. From the above analysis it can be concluded that the materials produced from the CSA and CSA800 powders meet the criteria for less demanding applications of general-purpose tools $[2,3]$.

\section{References}

[1] Konstanty, J. (2003). Cobalt as a matrix in diamond impregnated tools for stone sawing application, $\mathrm{PhD}$ thesis, $2^{\text {nd }}$ Edition, AGH University of Science and Technology, Krakow, Poland.

[2] Konstanty, J. (2005). Powder Metallurgy Diamond Tools, Elsevier, Oxford.

[3] Konstanty, J. (2013). Sintered diamond tools: trends, challenges and prospects. Powder Metallurgy. 56(3), 184188.

[4] Romański, A. (2015). Development of metal matrix for sintered diamonds tools. Kraków: AGH University of Science and Technology, Poland. (In Polish).

[5] Borowiecka-Jamrozek, J. (2013). Engineering structure and properties of materials used as a matrix in diamond impregnated tools. Archives of Metallurgy and Materials. 58(1), 5-8. DOI: 10.2478/v10172-012-0142-0

[6] Rimlinger, S. (1999). Cobalt and cobalt - containing binders for the diamond tools industry. The cobalt conference, The Royal Garden Hilton, London, England, 144.

[7] Konstanty, J. \& Bunsch, A. (1991). Hot pressing of cobalt powders. Powder Metallurgy. 34(3), 195-198.

[8] Borowiecka-Jamrozek, J. \& Konstanty, J. (2014). Microstructure and properties of a new iron-base material used for the fabrication of sintered diamond tools. Advanced Materials Research. 1052, 520-523. DOI: 10.4028/ www.scientific.net/AMR.1052.520

[9] Borowiecka-Jamrozek, J. \& Lachowski, J. (2014). Numerical modelling of stress/strain field arising in diamondimpregnated cobalt. Archives of Metallurgy and Materials. 59(2), 443-446. DOI: 10.2478/amm-2014-0073

[10] Borowiecka-Jamrozek, J. (2013). Microstructure and properties of hot pressed $\mathrm{Fe}-50 \% \mathrm{Co}$ materials. In $22^{\text {nd }}$ International Conference METAL2013 (pp.1432-1437). Brno, Czech Republic, Thomson Reuters database.

[11] Mechnik, A.(2014). Production of diamond-(Fe-Cu-Ni-Sn) composites with high wear resistance. Powder Metallurgy and Metal Ceramics. 52(9-10), 577-587.

[12] Konstanty, J., Tyrała, D. \& Radziszewska A. (2009). Ironbase materials manufactured from premixed powders by the hot press process. Archives of Metallurgy and Materials. 54(4), 1051-1058.

[13] Nanbin, H. \& Dianyue, G. (2013). The application development of Chinese multi-element pre-alloyed metal powders in diamond tools. Diamante, Applicazioni \& Technologia. Diecembre 2013, 23-30.

[14] CSA series Basic Alloy powder for Diamond Tools. (2013). User's Manual, Henan CUT-Stone Science \& Technology, CO., LTD, Zhengzhou.

[15] Borowiecka-Jamrozek, J. (2015). Microstructure and properties of hot pressed iron bronze powders. In $24^{\text {th }}$ International Conference METAL 2015, Brno, Czech Republic, Paper will be added to the conference proceedings of full text for publishing in Thomson Reuters database. 